\title{
Intertwined Effects of Gender and Migration Status on Persistence in SET
}

\section{Study Programs}

\section{Elisabeth Anna Guenther, Sabine T. Koeszegi}

Institute for Management Science, TU Wien, Vienna, Austria

TU Wien, Institute for Management Science

Theresianumgasse 27, 1040 Wien, Austria, sabine.koeszegi@tuwien.ac.at

This is an Accepted Manuscript of an article published by Taylor \& Francis in European Journal of Engineering Education on 6 Sep 2016, available online http://www.tandfonline.com/doi/abs/10.1080/03043797.2016.1228613

Please cite as

Guenther, Elisabeth Anna and Sabine Theresia Koeszegi. 2016. "Intertwined Effects of Gender and Migration Status on Persistence in SET Study Programmes. " European Journal of Engineering Education (Published online: 06 Sep 2016).

When referring to this paper, please check the page numbers in the published version of the journal. 


\title{
Intertwined Effects of Gender and Migration Status on Persistence in SET Study Programs
}

\begin{abstract}
This paper explores the intersectional interference of gender and migration status on students' persistence at an Austrian University of Technology. While controlling for the pre-university education and performance indicators, we estimate the odds for the persistence of male and female students, as well as of students with diverse migration statuses. We use the enrolment data of students from 1998-2010. The analysis reveals remarkable and significant effects of gender and migration status, as well as intersectional interference effects from both social categories on persistence. Female and students with immigration status are less likely to persist, even if performance and previous relevant experiences are controlled. A segregated analysis of the student population sheds further light on the interlocked and entangled effects of the social ascriptions underlying gender and migration status. The analysis supports the proposition of the accumulation of (dis-)advantages along students' careers. The profound quantification of gender and migration status effects can be utilized as basis for further research and purposeful policy measures to increase persistence in SET for students with diverse backgrounds.
\end{abstract}

Keywords: gender, migration status, intersectionality, science education, inequality

\section{Introduction}

Trajectories of students within science, engineering and technology (SET) are shown to be influenced by social dynamics (i.a. Ohland et al. 2011). The impact of social categories, e.g. gender, has been demonstrated with descriptive data in numerous studies (e.g. Bean 1982; Berryman 1983; Horwath, Kronberger, and Wörtl 2008; Ihsen, Höhle, and Baldin 2010; Ratzer et al. 2006). The main benefit of such approaches is to substantiate in an accessible and comprehensible way that inequality exists within SET. Along with this benefit comes the pitfall of over-simplifying social reality, homogenizing diverse groups, and therefore overlooking underlying patterns of inequality. A way to address this potential pitfall is offered by the intersectional framework, which examines the mutually influenced and entangled relationship of social categories (Anthias 2013; McCall 2005). In this paper we therefore address the intertwined effects of several social categories: gender, migration status ${ }^{1}$, age and pre-university education. We comprehend both, gender and migration status, as social constructs: gender as the perceived difference attributed to sex and migration status as ascribed qualities towards citizenship and perceived country of origin.

Despite meritocratic beliefs, social dynamics underlying categories such as gender or migration status do impact career chances within SET. Figures for female and male participation in SET reveal a high degree of gender segregation not just in Austria (uni:data) or the European Union (EC 2009; EC 2012; EC 2015) but actually in many OECD-Countries (Charles and Bradley 2009). At the European level, only one out of three researchers in SET is female (this ratio remains more or less unchanged over the last years: EC 2009; EC 2012; EC 2015). At the three Austrian SET universities (TU Wien, Graz University of Technology and Montanuniversität Leoben) the proportion of women ranges between $5.5 \%$ at the level of

1 Migration status is divided into (1) first generation immigrants (non-Austrians with preuniversity education outside Austria), i.e. international students, (2) second-generation immigrants (non-Austrians with an Austrian pre-university education), and (3) Austrians. The latter also includes naturalized migrants as well as people, born in Austria, with Austrian citizenship, and migration experiences themselves, e.g. pre-university education outside Austria. 
full professor and $27.9 \%$ among students (uni:data). Furthermore, in contrast to other disciplines, the so-called leaky pipeline phenomenon takes effect starting at the students' level: At the Austrian SET universities the proportion of female post-graduates is lower compared to the percentage of female beginners (uni:data).

The impact of social categories concerning migration status in pursuing SET is less examined than gender. This is all the more surprising, as students with immigration status constitute an important social group, e.g. $29.4 \%$ of all female and $23.2 \%$ of all male students at Austrian SET Universities are non-Austrians (uni:data).

Overall, only every second student graduates within the average study period (bm:wf 2011). Several empirical studies indicate that female SET students face a higher dropout risk than their male peers (cf. for Austria: Horwath, Kronberger, and Wörtl 2008; Ratzer et al. 2006; Wächter 2007). Also immigrated students face a higher dropout risk (Zaussinger et al. 2012). Several studies on students' dropout examine the reasons students leave through utilizing questionnaires (i.a. Derboven and Winker 2010; Heublein, Richter, and Schmelzer 2012; Horwath, Kronberger, and Wörtl 2008; Unger et al. 2009). They focus on individuals and the particular circumstances that influence their opt out decisions. While these studies shed light on different influences on students' persistence, they fail to quantify the entangled inequality processes associated with gender and migration status on a structural level.

In this paper we take a quantitative approach to estimate the impact of gender and migration status on students' persistence in SET. We use enrolment data with more than 100,000 data sets from study programs of an Austrian SET university between September 1998 and June 2010. This data allows tracking multiple cohorts throughout their educational careers and quantifying students' dropout rates. Logistic regression analysis is used to estimate the odds for students' persistence and to examine the change in odds caused by gender, migration status, age and pre-university education. The disaggregated analysis of student data further contributes to the identification of trajectories (cf. Ohland et al. 2011) and allows considering the "intersectional interference" of social categories"

In the following section we review relevant literature and provide a compact outline of our theoretical approach. Section three presents the data and method used to estimate the effect of gender and nationality on students' persistence. Section four provides the results. Findings and limitations are discussed in section five.

\section{Theoretical Background}

Students' decisions to either leave a university or to persist are influenced by several factors. Swail et al. (2003) condense these factors along three axes: cognitive, institutional, and social factors. Cognitive factors sum up issues concerning the students' ability to cope with a study program, e.g. time and self-management. Institutional factors combine all regulations and policies implemented by a higher education institution, e.g. curricula. Interactions with family, friends, colleagues, or faculty, as well as social background, laws, and other similar factors are subsumed in the social dimension. So in addition to the students' individual characteristics and skills, there are institutional factors to be considered, which of course also

2 The metaphor 'intersectional interference' (cf. Verloo 2013) refers to the physical phenomenon of superimposing waves. This metaphor highlights that the interplay of social categories is complex and in no way mechanistic, particularly since there are several factors that are diffracting the patterns. Intersectional hereby signifies the 'relationships among multiple dimensions and modalities of social relations and subject formations' (McCall 2005, 1771). 
impact the individual processes leading to attrition or persistence. Bean (1982) shows, e.g., how women and men are differently influenced by the courses offered by a university or which educational goals are set, both of which impact indirectly and directly the itent to leave a program.

Another aspect that can be taken into consideration is to become part of a university's social sphere, which is facilitated if students become integrated both academically and socially (Tinto 1975). Such integration process is, however, hallmarked by several thresholds which can become hindrances for female and minority students (Best, Sanwald, and Ihsen 2013; Haines, Wallace, and Cannon 2001; Jensen and Bøe 2013; Primack and O'Leary 1993; Robnett 2013). Even though there are indicators for a closing gender gap in engineering education, small hinderances can disadvantage female students (Vogt, Hocevar, and Hagedorn 2007). It is argued that these individual hindrances are not enormous, overt barriers but rather invisible micro-inequalities that female and minority students accumulate during their academic career (Haines, Wallace, and Cannon 2001; Welde and Laursen 2011). It is therefore necessary to extend the analysis on to the entire career of a student (Ferree and Purkayastha 2000).

Along students' career there are several critical thresholds. First of all, a domainspecific education prior to university registration constitutes an advantage in SET study programs (cf. Berryman 1983). The Austrian schooling system is highly fragmented and offers, aside from vocational training, several secondary schools including Technical and Crafts Colleges ${ }^{3}$. Since students attending Technical and Craft Colleges already have basic training in SET and are more familiar with the engineering culture, they bring in domain specific experiences (cf. Horwath, Kronberger, and Wörtl 2008; Kronberger and Horwath 2013). Domain specific knowledge can be a crucial starting advantage, since 'the institution's preferences for particular styles of academic behavior' (Tinto 1975, 104) influence one's grades. In general, women are underrepresented at Technical and Craft Colleges; currently only one out of four pupils at a Technical and Craft College is female (Radinger and SommerBinder 2013). Female students, with or without migration background, are less inclined to start a program in engineering or science (uni:data) ${ }^{4}$. Since SET is perceived masculine (Burack and Franks 2004; O'Keeffe 2013; Pillis et al. 2008; Pourrat 2005; Sagebiel and Dahmen 2006), it can be challenging for female students to choose engineering as a major, especially when parents, friends, or peers do not support such decisions (Ihsen, Höhle, and Baldin 2010). Adolescent girls report having less support in pursuing a career in SET (Robnett 2013), which makes it more difficult for them to choose a SET program.

Secondly, after entering a SET study program academic culture is crucial for persistence (Cech 2015; Fox, Sonnert, and Nikiforova 2011; Hartman and Hartman 2009; Tonso 2014). Very subtle mechanisms discourage non-typical, marginalized students from contacting faculty. As was shown in different social contexts like Japan (Hosaka 2013), the USA (Swail, Redd, and Perna 2003; Tinto 1997), Germany (Derboven and Winker 2010; Wolffram, Derboven, and Winker 2009), or Austria (Kronberger and Horwath 2013; Unger et al. 2009), interaction with faculty firmly influences the persistence of students. Female students are less likely to contact faculty (Hosaka 2013). They feel discouraged by the teaching style of lecturers or fear being perceived as incapable. Furthermore, female students report a non-inclusive culture, where their competence is constantly questioned (Best,

3 https://www.bmbf.gv.at/enfr/school/schools.html provides an overview of different school types in Austria (last access 21.07.2016)

$4 \quad$ For instance, in Austria $72 \%$ of all students in engineering are male. Altogether, $17.5 \%$ of programs enrolled by female students and $38.7 \%$ programs enrolled by male students are SET programs. This distribution stays more or less the same if you look at foreign nationals separately (uni:data). 
Sanwald, and Ihsen 2013) and their self-identification with the professional identity is challenged (Cech 2015). Moreover, the campus culture, expressed in the current form of teamwork, impact gender-relations and self-perception in studying SET (Tonso 2006a; Tonso 2006b). Additionally, female students with migration background report feeling socially excluded (Wolffram, Derboven, and Winker 2009), which lowers persistence.

While research exists on the gendered exclusion mechanism within SET, the interplay of gender and migration status is rarely quantified. Existing quantitative studies often rely on questionnaires (cf. Derboven and Winker 2010) and sometimes explicitly exclude migrant students (Kronberger and Horwath 2013). Hence they do not cover the entire student population. Published (governmental) reports (bm:wf 2011; OECD 2014), which rely on enrolment data, do not display the interaction between gender and migration backgrounds. Moreover, these reports do not control for disciplines or previous education, and to our best knowledge, no previous study has tracked undergraduates' institutional persistence after graduation.

We therefore address the following research questions: To what extent are students' trajectories within SET impacted by the underlying social dynamics ascribed to gender and migration status? More specifically, to what extent do the ascription towards both social categories affect students' persistence even if they accumulate advantages during their academic career, e.g. domain specific education or performance? Are female and migrant graduates less likely to continue after graduation? How do gender and migration status interfere with each other and with other (social) categories such as pre-university education or age? We approach these questions by analysing secondary, administrative data. The main advantage of administrative data is that it allows for an examination of an entire, real-life population. The challenge and limit of this data is that social categories have to be approximated by available indicators to address the above-mentioned factors of socially shaped trajectories.

\section{Data and Method}

To unveil the effects of gender and migration status on students' persistence, we analyse enrolment data of an Austrian SET university (in the following referred to as 'the University'). We are able to estimate the odds for the whole student population enrolled at the University between September 1998 and June 2010. This data allows us to track students' persistence beyond graduation, given that we know whether or not a diploma graduate enrolled in a doctoral program. Raw data contains 104,596 data sets. We aggregated the data by student registration number. Each case (i.e. student) comprises information from all programs in which a student enrolled, the first and last term of enrolment, her/his age, gender, nationality, type of university entrance qualification, Erasmus program participation, and if applicable date of graduation. We cleaned the data for all students who never attended a course. $^{5}$ Therefore only students who showed some effort and completed at least one course

5 As there are currently only few regulations limiting matriculation to an Austrian university, some students matriculated, but never attended a course. We therefore excluded students who did not complete at least one course because we assume that those students only enrolled but never actually wanted to study the program. This 'free access' to a university program is under constant political discussion; hence there are many changes, especially the last years. Nevertheless, in the period examined in this paper no limiting regulations for Austrian and EU-citizens were effective (except for art and sport programs and since 2006 also for medical programs). Then again the 
are included in this analysis. In total the cleared data set covers 48,773 students. For the purpose of clarity, we confine our paper to models on persistence of diploma students ${ }^{6}$ and diploma graduates.

We use logistic regression to estimate the odds of persistence for undergraduates and graduates. One advantage of logistic regression method is that the estimated effect sizes can be directly interpreted as the change in the odds between indicators influencing a certain outcome, e.g. persistence, when everything else is held constant. We therefore can directly compare effect sizes associated with gender, migration status, and their interaction with other social categories on students' persistence. We do so by comparing the different odds ratio, meaning the change in the odds to persist rather than to drop out, if a student is e.g. female instead of male (assume, the odds to persist would be 1:1, an odds ratio of 0.5 would change them to 1:2). Moreover, we illustrate the different chances by calculating the predicted probability of a hypothetical student, who is 19 years old (the majority of beginners are between 19 and 20 years old) when enrolling civil engineering (which is our reference category, as we explain below). This hypothetical student graduated from a Realgymnasium (which is our reference category for pre-university education) prior studying at the University; the program was her/his first choice. We will show how the likelihood to persist varies between gender groups as well as for students with or without immigration status.

\section{Dependent variable}

Our dependent variable is persistence. Persistence in our understanding signifies the students' willingness to either graduate (in the undergraduate program) or continue in a postgraduate program at the University. Hence, students who switched programs, for instance from business informatics to computer sciences, are counted as persistent and subsumed under the category 'more than one program enrolled'. Students who switched universities are counted as dropouts for the University (yet they might have graduated at another institution). We chose this definition to reveal the scope for action of the University. We code persistence/graduation ' 1 ' and drop/opt out ' 0 '. We defined all students as dropped out, if they neither enrolled in 2009/10 nor graduated until June 2010.

\section{Independent variables}

In order to reveal potential interference effects, we contrast the odds of the total population and those of the subpopulations. The subpopulations are disaggregated (1) by gender and (2) by the country of university entrance qualification (UEQ). We disaggregate by country of the UEQ instead of nationality, because we want to control the impact of previous education. In doing so, students within one subpopulation have comparable educational experiences. Furthermore the country of UEQ is, with nationality, one indicator of migration status.

situation is a bit more complicated for non-EU-citizens, especially if they obtained their university entrance qualification outside Austria. Here it depends (1) on the nationality and whether or not there are specific bi-national agreements (2) as well as on the university they want to start to study. For those students it is not as easy to change from one university to another as for Austrians. A short overview on admission for non-Austrians can be found at http://www.studyinaustria.at/study in austria/admission/ (last access 21.07.2016)

6 The former diploma program combined more or less the Bologna study architecture of bachelor and master programs. Hence, diploma degrees are more or less equivalent to a master degree. In order to distinguish the different types of program, we use this terminology. 
As was shown, students' persistence is influenced by many factors; some of them accumulate over time. We build our model accordingly. We first enter gender and nationality as demographic variables, since they precede other steps within the academic career. Gender is coded male ' 0 ' and female ' 1 '. Nationality indicates migration status and is coded ' 0 ' for Austrian and ' 1 ' for non-Austrian (i.e. immigration status). Students, who obtained their UEQ in Austria but are citizens of another country are seen as second generation immigrants, whereas non-Austrians with a foreign UEQ are defined as first generation immigrants or international students. The data unfortunately does not provide information about naturalization of migrants, which clearly is a limitation of this study. Nevertheless, the naturalization-rate in Austria is quite low $^{7}$ therefore this constitutes a minor bias.

Since the Austrian secondary education is highly fragmented, UEQ can be obtained in several different ways. Out of them, Technical and Craft Colleges and Realgymnasium ${ }^{8}$ provide the most favourable pre-conditions for studying SET in Austria. Students with another Austrian UEQ may enter university with an experience gap, which lowers their persistence (Horwath, Kronberger, and Wörtl 2008; Kronberger and Horwath 2013). We, therefore, included a set of dummy variables for different types of UEQ, including nonAustrian as one of them. Realgymnasium serves as a reference category. Realgymnasium is chosen because its gender distribution is close to the total population.

We operationalize the students' entrance decision using their enrolment behaviour. We assume students who feel very confident in their study choices will start their chosen program immediately after graduating secondary school. Therefore we include two variables for initial study decisions: difference in matriculation/enrolment year and age. Since there are few formal regulations ${ }^{9}$, students can change disciplines and/or universities ad libitum. Consequently the year of matriculation at an Austrian university does not have to correspond with the year of registration at the University. We assume that students who are determined in their study choice choose their preferred university straight away. Therefore we introduce a variable which indicates whether a student started a program at the University the same year she/he matriculated as a student in Austria. Additionally, age, although a demographic variable, serves as an indicator, as students who are older are less likely to come directly from secondary school. Introducing age as an explanatory variable is also supported by the fact that the older a student is, the less she/he is inclined to science (Jensen and Bøe 2013).

The student enrolment data does not provide information on grades. However, it includes information about students' participation in the international exchange program Erasmus, which can be used as performance indicator. More or less every third student has studied or plans to study for some time in another country (Unger et al. 2012). During the time interval that is examined in this paper, only advanced students with academic achievements and good grades were accepted in the Erasmus program. Therefore it is safe to use Erasmus participation as a performance proxy. We also introduce an interaction term of Erasmus program participation and the country of the UEQ to control for those students with a foreign UEQ who came to the University via this exchange program.

In addition to the indicators already mentioned, we control for discipline. We consider the variation within disciplines and potentially moderating effects of different learning cultures (Hartman and Hartman 2009). For the purpose of clarity the estimated odds for

7 According to Statistics Austria, the federal statistics institution, the naturalization rate of the time in question ranges between 0.7 and 6\% (last accessed 21.07.16).

8 Realgymnasium is a Secondary academic school emphasizing mathematics and science.

9 See note 5 
disciplines, which are entered in a set of dummy variables, are accessible via our website (see Appendix 1.3. and Appendix 2.2).

\section{Description of the Student Population}

We apply our model on two subpopulations: diploma students, who started their program between 1998 and 2001, and diploma graduates (from 1998-2010). The diploma program preceded the current bachelor and master program, which was introduced by the first schools in 2002. We therefore confine our analysis on the diploma cohorts until 2001. A diploma degree is comparable with a masters' degree, yet there is not the intermediate step of a bachelor degree, which was introduced with the Bologna study architecture. Along with this implementation diploma programs expired - in some schools faster than in others. At this time students, who were not able to graduate before their diploma program expired, could either get ex-matriculated or change to the new bachelor program. We excluded the 1,230 students who left the diploma program and switched to a bachelor program, as they did not leave the University immediately (it is possible for them to either drop out or graduate the other program). ${ }^{10}$ This way, we only consider data of students who indeed dropped out or persisted in the diploma program.

In total, out of 7,069 diploma students, who enrolled in 1998-2001, 4,648 dropped out. Only every third diploma student persisted at the University. The retention rate varies between $14.6 \%$ in business informatics, $45.6 \%$ in technical physics, and $65.8 \%$ for students who enrolled in more than one discipline (Appendix 1.1.3). Students of a joint program in business informatics between the University and a partner university show an even lower retention rate $(4.9 \%)$ at the University, although it is possible that they graduated at the partner university.

Figure 1: Ratio of Non-Austrian diploma students at the University (1998-2001)

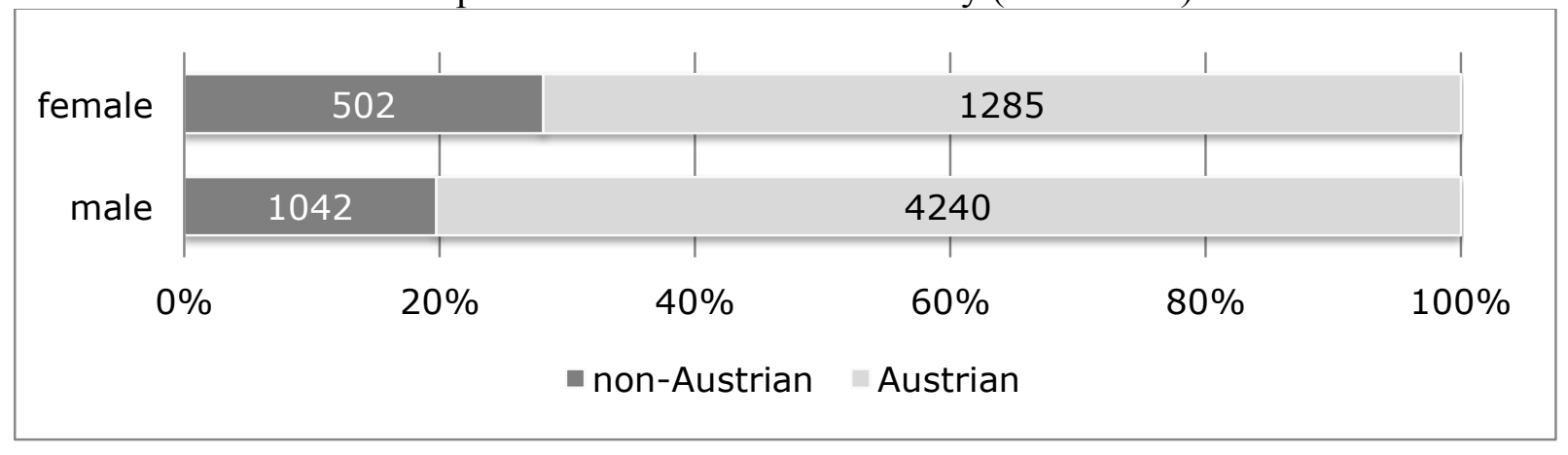

During the examined time interval, the University offered study programs in thirteen different disciplines. A horizontal segregation of female and immigrant students can be observed within these disciplines. The proportion of female diploma students, who enrolled between 1998-2001, ranges from $49.3 \%$ in architecture to $10.4 \%$ in mechanical engineering (Appendix 1.1.1). The ratio of non-Austrian citizens also differs considerably between disciplines. While only $6 \%$ of technical mathematics diploma students are non-Austrian, this group constitutes $41.5 \%$ of mechanical engineering students (Appendix 1.1.2). In general the ratio of non-

10 Out of the 1,230 students who switched to the bachelor program, 889 graduated or persisted in the chosen bachelor program and 341 dropped out. With $27.7 \%$ of drop out, this group has a distinctively higher persistence rate, at least until obtaining the first degree. Out of the 553 students who graduated a bachelor program, 408 (73.8\%) also enrolled a master program; which means that 145 diploma dropouts left the University with a bachelor degree. 
Austrian students is higher within the female versus the male subpopulation (Figure 1). While $28 \%$ of female diploma students were non-Austrians, one out of five male diploma students enrolled at the University between 1998 and 2001 was citizen of another country.

On average, diploma students were 22.48 years old when enrolling in a diploma program at the University. Students who persisted are on average younger (21.155) than those who dropped out (23.170). About one in three students obtained the UEQ at a Realgymnasium (31.6\%) and about one in four students at a Technical and Crafts College (24.9\%). $22.0 \%$ of all diploma students enrolled at the University with a foreign UEQ, which leaves $12.5 \%$ with a degree from an academic secondary school, $6.9 \%$ with a degree from another vocational college, and $2.1 \%$ with other forms of UEQ. Out of the 7,069 diploma students included in our estimations, 483 participated in the Erasmus program $(6.8 \%$; for further details see Appendix 1.2.).

\section{Results}

\section{Persistence in Diploma Programs}

Students who started their diploma program between winter term 1998 and summer term 2001 are included in the logistic regression models. The change in odds shows whether a student is more likely to have dropped out (coded 0) or persisted (graduated or continued studying; coded 1) at the University up until 2010. In total the data from 7,069 students are included in these estimations (Table 1).

Table 1: Persistence in Diploma Program

\begin{tabular}{|c|c|c|c|c|c|}
\hline & $\begin{array}{c}\text { Total } \\
\operatorname{Exp}(\beta)\end{array}$ & $\begin{array}{l}\text { Female } \\
\operatorname{Exp}(\beta)\end{array}$ & $\begin{array}{c}\text { Male } \\
\operatorname{Exp}(\beta)\end{array}$ & $\begin{array}{c}\text { Foreign } \\
\text { UEQ } \\
\text { Exp }(\beta)\end{array}$ & $\begin{array}{c}\text { Austrian } \\
\text { UEQ } \\
\operatorname{Exp}(\beta)\end{array}$ \\
\hline Gender $(0=$ male; $1=$ female $)$ & $0.709 * * *$ & - & - & 1.758 & $0.701 * * *$ \\
\hline $\begin{array}{l}\text { Nationality } \\
(0=\text { Austrian; } 1=\text { non-Austrian })\end{array}$ & $0.567 * *$ & 0.623 & $0.590 *$ & $0.449 * * *$ & $0.610 *$ \\
\hline Interaction Term Gender \& Nationality & 1.346 & - & - & 0.548 & 0.956 \\
\hline \multicolumn{6}{|c|}{ University Entrance Qualification (UEQ) Reference: Realgymnasium } \\
\hline Technical and Crafts Colleges & $1.185 *$ & 0.840 & $1.250 * *$ & - & 1.128 \\
\hline Secondary Academic School & 1.138 & 1.156 & 1.114 & - & 1.149 \\
\hline Vocational College & 0.772 & $0.598 *$ & 0.896 & - & 0.779 \\
\hline Other Types of UEQ & 0.806 & 0.637 & 0.860 & - & 0.802 \\
\hline Foreign UEQ (fUEQ) & 1.299 & 1.862 & 1.034 & - & - \\
\hline Interaction Term fUEQ \& Nationality & $0.542 *$ & 0.454 & 0.661 & - & - \\
\hline Age at Matriculation & $0.930 * * *$ & $0.954 *$ & $0.919 * * *$ & $0.914 * * *$ & $0.943 * * *$ \\
\hline $\begin{array}{l}\text { Enrolled in the Year as matriculated } \\
(0=\text { no; } 1=\text { yes })\end{array}$ & $1.373 * * *$ & 1.053 & $1.471 * * *$ & 0.783 & $1.654 * * *$ \\
\hline Erasmus Program $(0=$ no; $1=$ yes $)$ & $10.707 * * *$ & $15.538 * * *$ & $9.574 * * *$ & $25.938 * * *$ & $10.543 * * *$ \\
\hline Interaction Term Erasmus \& FUEQ & 2.117 & 3.781 & 1.614 & - & - \\
\hline Constant & 0.989 & 0.479 & 1.137 & 1.179 & 0.694 \\
\hline $\mathrm{N}$ & 7069 & 1787 & 5282 & 1556 & 5513 \\
\hline Nagelkerke $\mathrm{R}^{2}$ & 0.326 & 0.304 & 0.342 & 0.253 & 0.328 \\
\hline
\end{tabular}

All else equal, migration status (indicated by nationality and country of UEQ) and gender have a strong impact on persistence. The odds for non-Austrian male students to persist are decreased by a factor of 0.567 compared to Austrian male students. Female 
students' odds to persist are reduced by 0.709 compared to male students, ceteris paribus. Interestingly, the interaction term slightly offsets the combined effect of gender and migration status. To illustrate this, we calculate and compare the predicted probability for a 19 year old student who started studying civil engineering at the University directly following graduation from a Realgymnasium: The predicted probability of persistence is $48.5 \%$ when this is an Austrian male student. When this Austrian student is female, the predicted probability decreases to $40.0 \%$. When this male student is non-Austrian, the predicted probability is only $34.8 \%$. When this student is female and non-Austrian, the probability is $33.7 \%$. Hence, the estimated disadvantages of migration status and female gender show an intersectional interference that decreases the chances of female migrant students less strongly as one would expect if both social categories - gender and migration status - are examined independently (see Figure 2).

Figure 2: Illustration of impact due to gender and immigration status for Austrian citizens and $2^{\text {nd }}$ generation immigrants on persistence in the diploma program

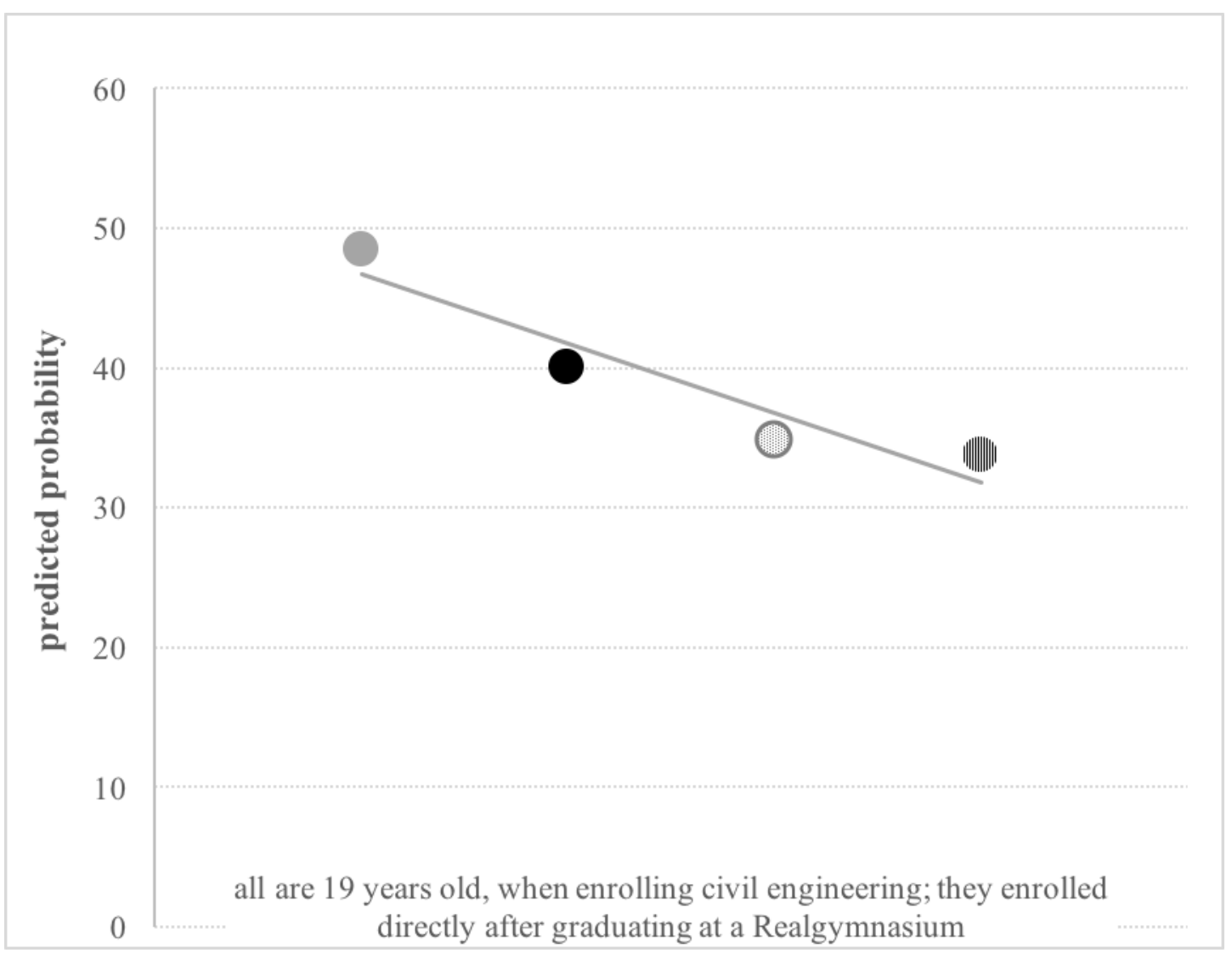

Contrasting subpopulations unveils further intersectional interference effects. Being a citizen of another country has a stronger impact within the male subpopulation $(0.590)$ than within the female subpopulation (0.623). Remarkably, the effect of migration status exists within both UEQ groups, i.e. it also occurs for students who obtained their entrance qualification in Austria. The odds for male students who graduated from an Austrian school but are citizens of another country, are reduced 0.610 times, all else equal. The effect of nationality, an indicator for migration status, is stronger for students with a foreign UEQ: the odds decrease by a factor of 0.449 for male international students, compared to male Austrians with foreign UEQ. To illustrate the magnitude: A student with foreign UEQ but Austrian citizenship, has more than twice times (2.227) better odds for persistence than an 
international student. All else equal, female Austrian citizens with an Austrian UEQ are less likely to persist than Austrian male students (reduction of odds by a factor of 0.701 ). The decrease in odds is stronger for female second generation immigrants (by a factor 0.409 when compared to male Austrian students). A similar decrease in odds can be observed for female international students: Within the foreign UEQ subpopulation the odds of female immigrants are reduced by a factor of 0.433 compared to an Austrian male student, ceteris paribus. Only for a very small group of females, the odds for persistence are better compared to their male counterparts. The chances to persist are for 57 Austrian female students with a foreign UEQ 1.758 higher than for the 119 Austrian male peers with a foreign UEQ, all else equal. We illustrate this discrepancy in displaying the corresponding predicted probability in Figure 3.

Figure 3: Illustration of impact due to gender and immigration status for Austrian citizens and international students $\left(1^{\text {st }}\right.$ generation immigrants $)$ on persistence in the diploma program

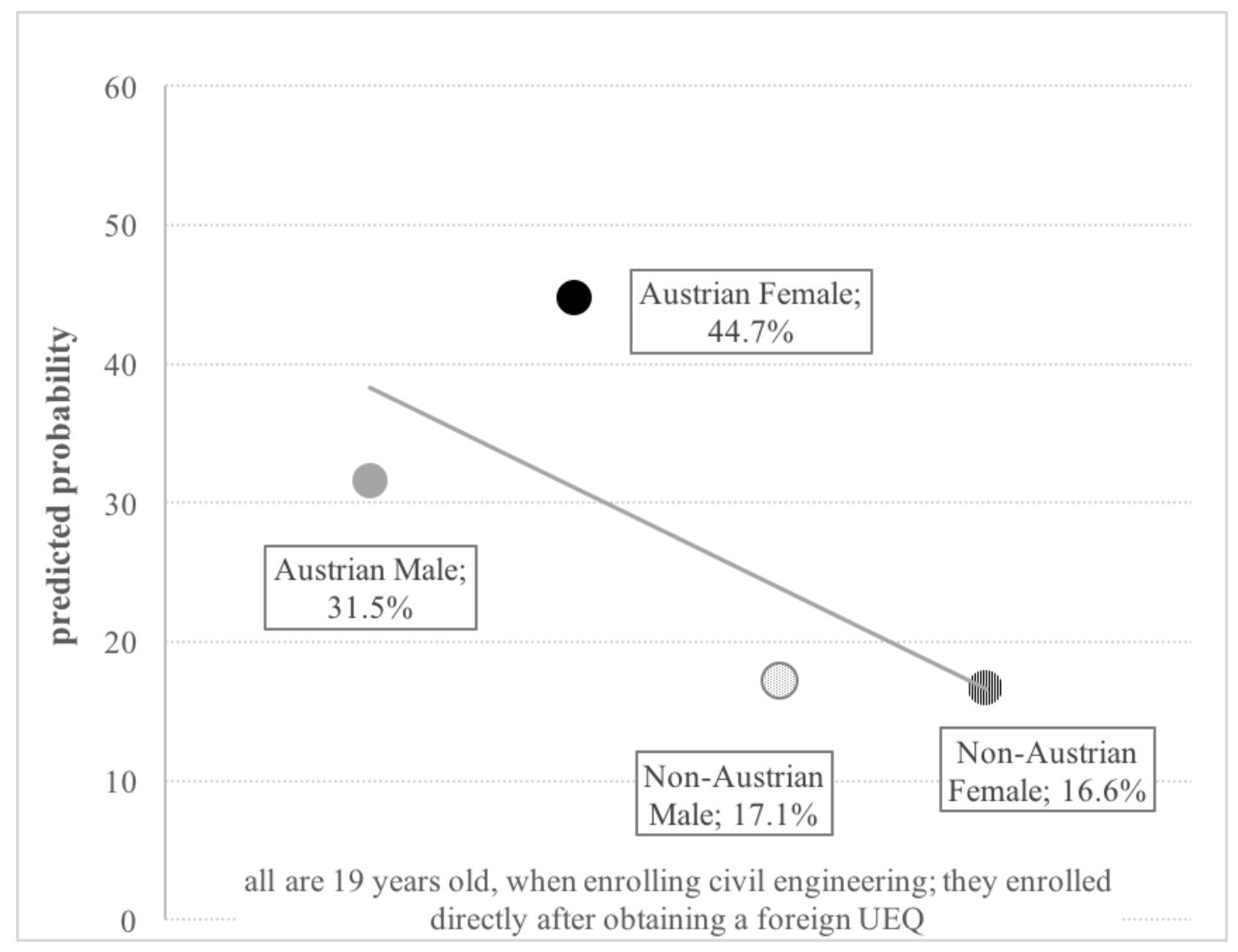

Previous education impacts the odds of male and female students differently. Domain specific education (Technical and Crafts Colleges) increases the odds of persistence by a factor of 1.185. Interestingly, this increase is stronger within the male subpopulations (1.250), but reversed for female students $(0.840)$. Furthermore, a vocational college degree (Technical and Crafts Colleges excluded) influences the odds of male students (0.896) less strong than those of female students (0.584). As for students with foreign UEQ, retention is increased by a factor of 1.299 if the student is Austrian. The differences between both gender populations are intriguing and correspond to the gender effect within both UEQ subpopulations; within the female subpopulation, foreign UEQ increases the odds by a factor of 1.862 (for Austrians), while for male Austrian students this shows little effect (1.034). International students on the 
other hand are less likely to persist, especially if they are male. Within the female subpopulation this status reduces the odds to persist by a factor of 0.527 and within the male subpopulation by the factor of 0.403 . Hence, only students with Austrian citizenship benefit from a foreign UEQ; moreover there is an interaction effect between gender and migration status.

The older a student is upon matriculation, the less likely she/he is to persist. For every year a student is older, her/his odds to retain are reduced by the factor 0.930 . This effect is less pronounced for female students (0.954) than for male students (0.919). This difference accumulates with time. If a female beginner is three years older than another female beginner, the odds for persistence are reduced by a factor of 0.868 ( 0.954 to the power of 3$)$. For male beginners the odds decrease by the factor 0.776 within three years $(0.919$ to the power of 3$)$. As for UEQ, students with previous Austrian education also display a weaker effect for age (0.943 year) than students with a foreign UEQ (0.914). In summary, the impact of age is stronger within the male subpopulation and among students with a foreign UEQ. This impact of age indicates a higher retention of students, who start studying directly following graduation from secondary school. This is supported by the increase in odds (1.373) if a student enrolled at the University the same year she/he matriculated in Austria. Here, again, the effect is stronger within the male subpopulation (1.471). At the same time, it shows only minimal effect for female students (1.053). Contrary to age, this indicator of Determined Study Choice acts positively for students with an Austrian UEQ (an increase by the factor 1.654) and decreases the odds for students with a foreign UEQ (0.783).

The performance indicator Participation in the Erasmus Program strongly increases the odds to persist. This was an expected result, since only advanced students are able to participate in the exchange program. The difference between the subpopulations is significant. While the odds for male students change by a factor of 9.574 , the odds for female students increase 15.538 times, if they participated in the Erasmus program and have an Austrian UEQ. Surprisingly, the odds to persist increase even more for students with a foreign UEQ.

\section{Continuation from Diploma Graduates to a Doctoral Program}

Along an academic career, enrolment in a doctoral program is the step following a diploma degree. Approximately every fourth diploma graduate from 1998 to 2010 enrolled a doctoral program at the University. In the models presented below, we estimated the odds of a diploma graduate either leaving the University (coded 0 ) or enrolling in a doctoral program (coded 1 ). All 4,638 diploma graduates from 1998 to 2010 were included.

Gender and migration status show an effect with regard to continuation after graduation. Again, the data displays intersectional interference of both categories. The odds to persist after graduation are reduced by the factor 0.775 when the graduate is female, all else equal. Having an immigration status also reduces the odds to continue 0.486 times for males, and 0.785 for female students (with an interaction-effect gender and nationality of 2.083). For a better understanding, we again compare the predicted probability of a graduate with a Realgymnasium degree, who was 19 years old upon enrolment in civil engineering. The predicted probability for this diploma graduate to continue in a doctoral program is $23.4 \%$, when the graduate is an Austrian male. The probability changes to $19.2 \%$ when the graduate is female and to $12.9 \%$ for a male immigrant. A female immigrant has $19.3 \%$ predicted probability to continue after graduation. Hence in the case of persistence after graduation, the interference of gender and migration status benefits female immigrants compared to male immigrants. Nevertheless, Austrian male graduates constitute the group most likely to persist after graduation. 
Table 2: Continuation from Diploma Graduates to Doctoral Program

\begin{tabular}{|c|c|c|c|c|c|}
\hline & $\begin{array}{c}\text { Total } \\
\operatorname{Exp}(B)\end{array}$ & $\begin{array}{l}\text { Female } \\
\operatorname{Exp}(B)\end{array}$ & $\begin{array}{l}\text { Male } \\
\operatorname{Exp}(\mathrm{B})\end{array}$ & $\mid \begin{array}{c}\text { Foreign } \\
\text { UEQ } \operatorname{Exp}(B)\end{array}$ & $\begin{array}{c}\text { Austrian } \\
\text { UEQ } \operatorname{Exp}(\mathrm{B})\end{array}$ \\
\hline Gender $(0=$ male; $1=$ female $)$ & $0.775^{*}$ & - & & 1.681 & $0.751 *$ \\
\hline $\begin{array}{l}\text { Nationality } \\
(0=\text { Austrian; } 1=\text { non-Austrian })\end{array}$ & $0.486^{*}$ & 1.058 & 0.490 & $0.404 *$ & 0.487 \\
\hline $\begin{array}{l}\text { Interaction term } \\
\text { gender \& nationality }\end{array}$ & $2.083 *$ & & & 0.990 & 2.176 \\
\hline \multicolumn{6}{|c|}{ University Entrance Qualification (UEQ) Reference: Realgymnasium } \\
\hline Technical and Crafts Colleges & 1.198 & 1.224 & 1.217 & - & $1.225^{*}$ \\
\hline Secondary Academic School & 1.087 & 1.105 & 1.082 & - & 1.088 \\
\hline Vocational College & 0.951 & 0.880 & 1.021 & - & 0.984 \\
\hline $\begin{array}{l}\text { Other Types of University Entrance } \\
\text { Qualification }\end{array}$ & 1.087 & $\sim$ & 0.817 & - & 1.164 \\
\hline $\begin{array}{l}\text { Foreign University Entrance } \\
\text { Qualification (FUEQ) }\end{array}$ & $1.652 *$ & 2.183 & 1.480 & - & \\
\hline $\begin{array}{l}\text { Interaction Term FUEQ \& Austrian } \\
\text { Nationality }\end{array}$ & 0.670 & 0.412 & 0.784 & - & \\
\hline Age at Diploma Matriculation & $0.918 *$ & 0.970 & $0.901 *$ & 0.991 & $0.901 *$ \\
\hline $\begin{array}{l}\text { Enrolled in the Year as Matriculated } \\
(0=\text { no; } 1=\text { yes })\end{array}$ & $0.761 *$ & 0.768 & $0.776^{*}$ & 1.141 & $0.700 *$ \\
\hline $\begin{array}{l}\text { Erasmus Program } \\
(0=\text { no; } 1=\text { yes })\end{array}$ & 0.989 & 1.023 & 0.992 & 0.470 & 0.981 \\
\hline $\begin{array}{l}\text { Interaction Term } \\
\text { Erasmus \& FUEQ }\end{array}$ & $0.423 *$ & 0.546 & 0.402 & - & \\
\hline Constant & 0.442 & -0.838 & 0.797 & -1.308 & 0.888 \\
\hline $\mathrm{N}$ & 4,638 & 1,116 & 3,522 & 635 & 4,003 \\
\hline Nagelkerke $\mathrm{R}^{2}$ & 0.178 & 0.187 & 0.182 & 0.163 & 0.176 \\
\hline
\end{tabular}

Examining the subpopulations separately also reveals effects of intersectional interference. For instance, nationality has a miniscule impact on the odds to persist among female graduates (1.058), but strongly decreases the odds for male graduates (0.49). If the country of a UEQ is considered, immigration status also reduces the odds to persist after graduation. For male graduates with Austrian UEQ, immigration status reduces the odds by factor 0.487 , ceteris paribus. Within the subpopulation of graduates with a foreign UEQ the odds are reduced by a factor of 0.404 for male graduates. In contrast to male Austrian graduates with an Austrian UEQ, the odds of female non-Austrians are reduced by factor 0.796, all else equal, while the odds for female Austrian graduates are 0.751 times lower than for male Austrian graduates. Hence, compared to female Austrian graduates, women with immigration status are slightly more likely to persist, ceteris paribus. This changes if the subpopulation with a foreign UEQ is examined, where the odds for a non-Austrian female graduate decrease by the factor 0.672 compared to Austrian male graduates. Among students with a foreign UEQ, female Austrian graduates are more likely to persist after graduation than male Austrian graduates, all else equal (see Figure 5). 
Figure 4: Illustration of impact due to gender and immigration status for Austrian citizens and $2^{\text {nd }}$ generation immigrants on diploma graduates' likelihood to continue in a doctoral program

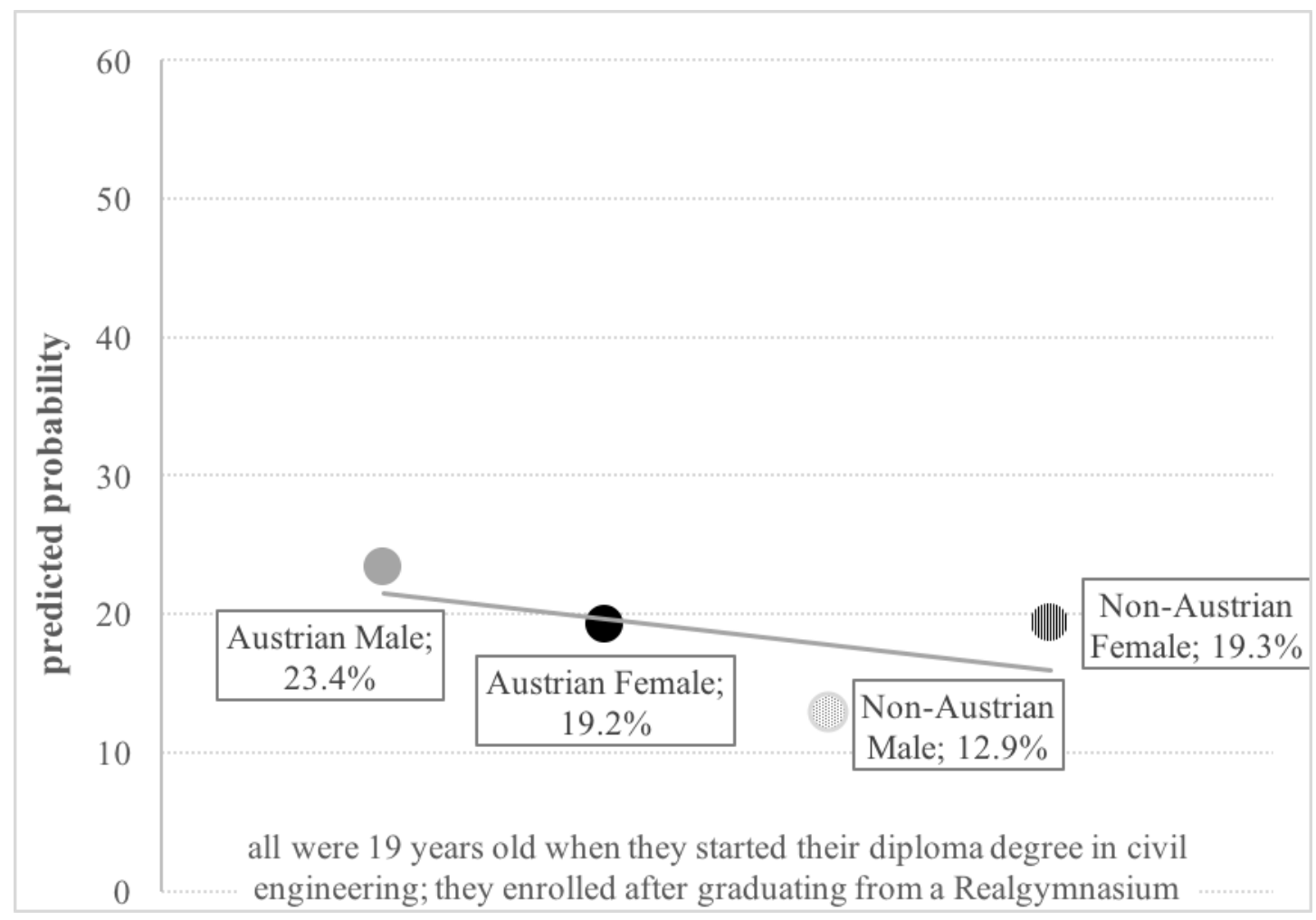


Figure 5: Illustration of impact due to gender and immigration status for Austrian citizens and international students' likelihood to continue in a doctoral program after diploma graduation

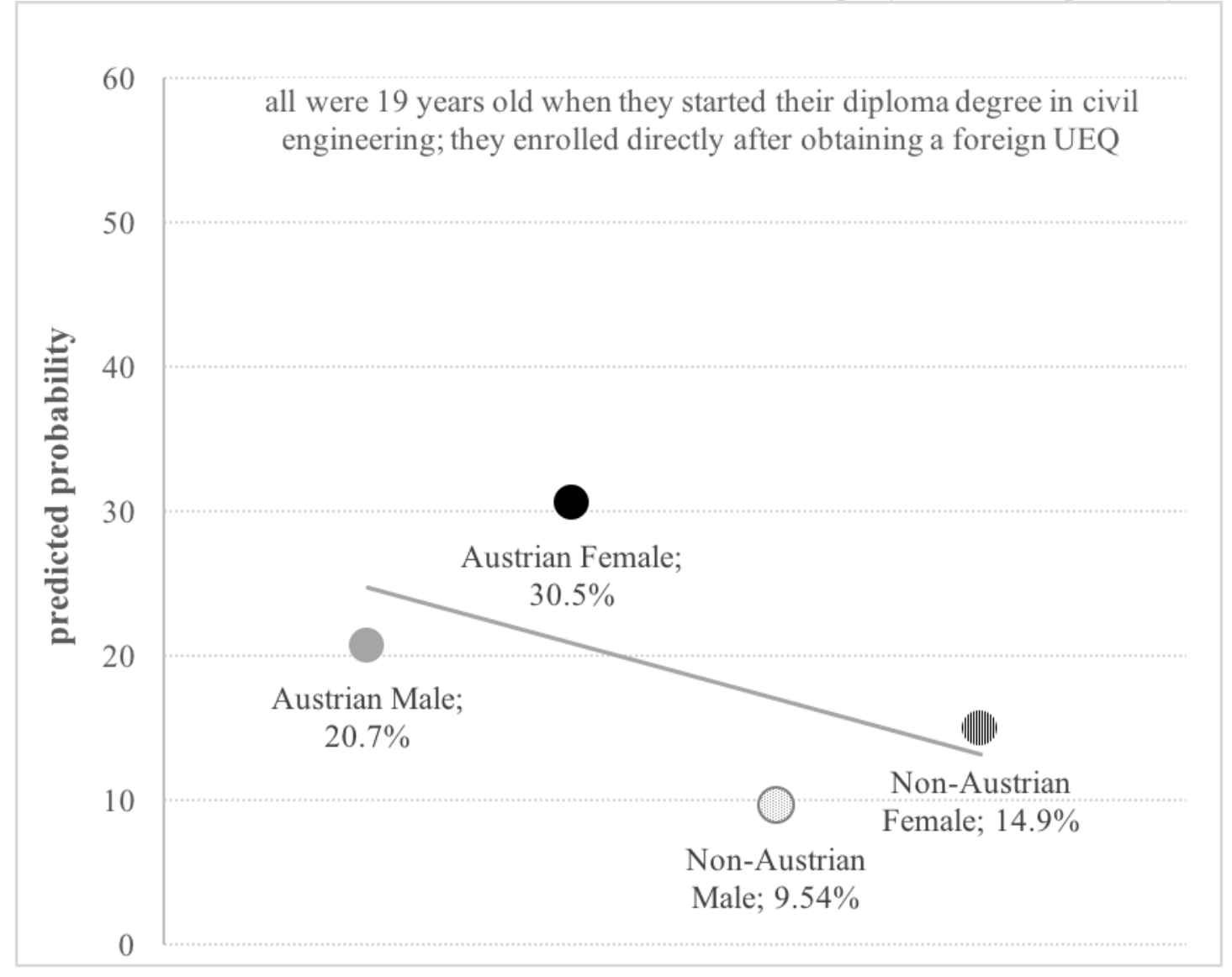

Graduates with domain specific education prior to enrolment are more likely to continue in a doctoral program. The odds to continue increase by the factor 1.198, if a graduate attended a Technical and Crafts College instead of a Realgymnasium. In this instance, there are only marginal differences between female and male graduates. Students with a foreign UEQ are more likely to continue, if they are Austrian. The interference of gender corresponds to the results already mentioned: Among female graduates, the odds are twice as high for Austrians with a foreign UEQ as compared to those with a Realgymnasium degree. Within in the male subpopulation this effect is only 1.480. If migration status is considered as well, it becomes clear that foreign UEQ itself does not necessarily reduce the odds. In both gender subpopulations, being a non-Austrian with a foreign UEQ reduces the odds to persist after graduation. This reduction is more pronounced within the male subpopulation (0.569, compared to Austrian Realgymnasium alumni) than within female subpopulation (0.952).

The older a graduate is when she/he first enrolled in a diploma program, the less likely this graduate is to continue in a doctoral program. Each year the graduate is older, the odds are reduced by factor 0.918 . This effect is weaker for female graduates $(0.97)$ and hardly noticeable for graduates with a foreign UEQ (0.991). It is, however, stronger for male graduates (0.902) and graduates with an Austrian UEQ (0.901).

The odds for persistence decrease (by a factor of 0.761 ), if the graduate enrolled at the University the same year that she/he matriculated at an Austrian university. While the difference between male and female subpopulations is quite small, this indicator has a 
different impact within both UEQ subgroups. The odds for graduates with an Austrian UEQ are reduced 0.7 times, whereas they increase by the factor 1.141 among graduates with a foreign UEQ. This indicates that graduates with an Austrian UEQ who changed from another university are more likely to stay at the University, whereas migrant graduates are more likely to stay if they had chosen the University from the start.

As for changes in the odds of graduates who participated in the Erasmus program, only small differences between both gendered subpopulations exist. Within the female subpopulation, participation in the Erasmus program slightly increases the odds to persist after graduation (1.023), whereas the odds slightly decrease (0.992) within the male subpopulation - if the graduate is an alumnus of an Austrian school. Contrary to the undergraduate program, participation in the Erasmus program halves the odds to persist after graduation if the graduate obtained her/his UEQ outside Austria. This indicates that mobile international students are more likely to leave the University after graduation.

\section{Summary and Conclusions}

Altogether the analysis of students' enrolment data unveils different trajectories for female and immigrant students when compared to Austrian male students. In the undergraduate program and after diploma graduation, Austrian male students with domain specific knowledge constitute the group most likely to persist. The reduced odds for female students to persist at the University - all other factors kept equal - are pronounced. Furthermore, immigration status reduces the odds to persist more strongly for international than for secondgeneration male immigrants in the undergraduate programs.

When it comes to the intertwined effects of gender and migration status, it appears that migration status has a moderating effect on the influence of gender on persistence. Although male students are - in general - more likely to persist, this is not the case for immigrants. Even though female undergraduate immigrants show a slightly smaller tendency to persist at the University than male immigrants, they are more likely to continue in a doctoral program after graduation. Hence, immigration status slightly increases the odds to persist after diploma graduation for female students, while it drastically reduces the odds for male students. Furthermore, it is interesting that the - small group of - female Austrian students with migration experience (through foreign UEQ) are more likely to persist than their male peers. The disadvantages generally ascribed to female gender are counterbalanced in these few cases. This result abides further investigation.

Generally, domain specific education increases the odds to persist, although this is not the case for female and male students to the same extent. Male undergraduates and graduates are most likely to persist if they attended a Technical and Crafts College. The odds for female undergraduates on the other hand are reduced, if they attended a Technical and Crafts College. Then again female graduates with Technical and Crafts College are more likely to continue in a doctoral program than other female graduates with an Austrian UEQ. Here, the increase in odds is more or less the same compared to male graduates. Furthermore the experience gap, indicated through a degree from another vocational college or other types of Austrian UEQ, reduces the odds for female students more than within the male subpopulation. Hence, the effect of previous education is clearly gendered. Moreover, it is interesting that pre-university education also impacts the odds of graduates to continue in a doctoral program. One could assume that undergraduates with fewer experiences prior to university would have caught up with their peers from Technical and Crafts Colleges upon graduation, especially since the University offers some 'bridge-classes' to ease the transfer from secondary school to university. Yet, the experience gap indicated by pre-education is effective. We therefore assume that the disciplinary culture enacted during the lectures and through the curricula privileges male students with domain specific pre-university education. 
As expected, performance, measured through participation in the Erasmus program, increases the odds to persist. Again, the strength of this indicator varies substantially in the different subpopulations. It is stronger within the female subpopulation than for male students. Since only advanced students are able to participate in the Erasmus program, this indicator also enters a time dimension in our estimations. It appears that female students, who attain this advanced level, are less likely to leave the University than male peers at the same stage. Since the impact is weaker within the male subpopulation, this signifies that either female students decide earlier or that the compensation of disadvantages through good performance is more important for female students. This effect could also be caused by external factors: The older a student the more likely she/he is to be employed (cf. Sarcletti and Müller 2011); the distinct difference between both subpopulations can partly be caused by the barriers female SET graduates encounter when they aim to work in their field of study (cf. Kirkup et al. 2010; Solga and Pfahl 2009). Further research is needed to substantiate these explanations.

Diploma students with a foreign UEQ who participated in the Erasmus program are more likely to persist than those who did not participate. Since the data does not differ between incoming and outgoing exchange students, we expected foreign Erasmus students to be incoming students and therefore more likely to drop out. Apparently this is not the case. Either, incoming Erasmus students decided to graduate at the University and prolonged their stay, or international students who initially started to study at the University also participated in the exchange program as outgoing students. It seems that students who already showed a high willingness for mobility, as graduates with a foreign UEQ and a participation in the Erasmus program do, are more likely to leave the University after graduation. Perhaps they already have more attractive job offers (cf. Bótas and Huisman 2013), or they simply move on to enhance their chances elsewhere. In any case, this factor affects international students differently than Austrian students. Further research is needed to elaborate on the processes leading to such differences.

Altogether our results substantiate a pronounced effect of gender and migration status on persistence and demonstrate that stereotyped students cannot compensate for discriminatory practices and dynamics. Effective retention management at universities, aimed at increasing low graduation rates in SET (i.a. Derboven and Winker 2010; van den Bogaard 2012), needs to consider these intersectional effects.

\section{Limitations}

Although our analysis offers insights to what extent social dynamics ascribed to gender and migration status shape the trajectories of students within SET, there are some issues we cannot address. Students' enrolment data does not provide any information on proficiencies and cognitive skills of students. Unfortunately, data on social background (e.g. class and the education level of students' parents) is also not available. Also, we are not able to further distinguish the type of pre-education for international students, which could shed more light on the dropout and persistence behaviour of these students. Such information would have enhanced our model in order to explain more of the variance.

\section{Glossary}

SET

UEQ

Realgymnasium
Science, Engineering and Technology

University Entrance Qualification

Secondary Academic School Emphasizing Mathematics and Science 


\section{Sources}

administrative data of the University

uni:data. Public database of the Austrian Federal Ministry of Science, Research, and Economy. http://www.bmwfw.gv.at/unidata (last accessed: 21.07.2016).

\section{References}

Anthias, Floya. 2013. "Moving beyond the Janus Face of Integration and Diversity Discourses: Towards an Intersectional Framing." The Sociological Review 61 (2): 323343. doi:10.1111/1467-954X.12001.

Bean, John P. 1982. "Student Attritions, Intentions, and Confidence: Interactions Effects in a Path Model." Research in Higher Education 17 (4): 291-320. doi:10.1007/BF00977899.

Berryman, Sue E. 1983. Who Will Do Science? Trends, and Their Causes in Minority and Female Representation among Holders of Advanced Degrees in Science and Mathematics. A Special Report. New York.

Best, Kathinka L, Ulrike Sanwald, and Susanne Ihsen. 2013. "Gender and STEM in Germany: Policies Enhancing Women's Participation in Academia." International Journal of Gender, Science and Technology 5 (3): 292-304.

bm:wf, Bundesministerium für Wissenschaft und Forschung. 2011. Universitätsbericht $>$ 2011. Wien.

Bótas, Paulo Charles Pimentel, and Jeroen Huisman. 2013. “A Bourdieusian Analysis of the Participation of Polish Students in the ERASMUS Programme: Cultural and Social Capital Perspectives." Higher Education, May. doi:10.1007/s10734-013-9635-7.

Burack, Cynthia, and Suzanne Franks. 2004. "Telling Stories About Engineering: Group Dynamics and Resistance to Diversity." NWSA Journal 16 (1): 79-95. doi:10.1353/nwsa.2004.0029.

Cech, Erin. 2015. "Engineers and Engineeresses? Self-Conceptions and the Development of Gendered Professional Identities.” Sociological Perspectives 58 (1): 56-77. doi:10.1177/0731121414556543.

Charles, Maria, and Karen Bradley. 2009. "Indulging Our Gendered Selves? Sex Segregation by Field of Study in 44 Countries." AJS; American Journal of Sociology 114 (4): 924 976. http://www.ncbi.nlm.nih.gov/pubmed/19824299.

Derboven, Wibke, and Gabriele Winker. 2010. Ingenieurwissenschaftliche Studiengänge Attraktiver Gestalten : Vorschläge Für Hochschulen. Ingenieurwissenschaftlich. Heidelberg [u.a.]: Springer.

EC, European Commission. 2009. She Figures 2009. Statistics and Indicators on Gender Equality in Science.

EC, European Commission. 2012. She Figures 2012. Gender in Research and Innovation. Statistics and Indicators.

EC, European Commission. 2015. She Figures 2015. doi:10.2777/744106.

Ferree, Myra Marx, and Bandana Purkayastha. 2000. "Equality and Cumulative Disadvantage: Response to Baxter and Wright." Gender \& Society. doi:10.1177/089124300014006007.

Fox, Mary Frank, Gerhard Sonnert, and Irina Nikiforova. 2011. "Programs for Undergraduate 
Women in Science and Engineering: Issues, Problems, and Solutions." Gender \& Society 25 (5): 589-615. doi:10.1177/0891243211416809.

Haines, Valerie A., Jean E. Wallace, and M. Elizabeth Cannon. 2001. "Exploring the Gender Gap in Engineering: A Re-Specification and Test of Tlie Hypothesis of Cumulative Advantages and Disadvantages." Journal of Engineering Education 90 (4): 677-684.

Hartman, Harriet, and Moshe Hartman. 2009. "Do Gender Differences in Undergraduate Engineering Orientations Persist When Major Is Controlled?" International Journal of Gender, Science and Technology 1 (1): 61-82.

http://genderandset.open.ac.uk/index.php/genderandset/article/viewArticle/56.

Heublein, Ulrich, Johanna Richter, and Robert Schmelzer. 2012. "Die Entwicklung Der Schwund- Und Studienabbruchquoten an Den Deutschen Hochschulen HIS : Forum Hochschule."

Horwath, Ilona, Nicole Kronberger, and Irmgard Wörtl. 2008. Das Technikstudium Aus Der Sicht von Frauen Und Männern TEquality - Technik. Gender . Equality. Edited by Gabriella Hauch. Linz: Land Oberösterreich, Büro für Frauenfragen.

Hosaka, Masako. 2013. “'I Wouldn’t Ask Professors questions!' Women Engineering Students' Learning Experiences in Japan.” International Journal of Gender, Science and Technology 5 (2): 149-169.

http://genderandset.open.ac.uk/index.php/genderandset/article/viewArticle/272.

Ihsen, Susanne, Ester Ava Höhle, and Dominik Baldin. 2010. Spurensuche!:

Entscheidungskriterien Für Natur-Bzw. Ingenieurwissenschaften Und Mögliche Ursachen Für Frühe Studienabbrüche von Frauen Und Männern.

Jensen, Fredrik, and Maria Vetleseter Bøe. 2013. "The Influence of a Two-Day Recruitment Event on Female Upper Secondary Students' Motivation for Science and Technology Higher Education." International Journal of Gender, Science and Technology 5 (3): 317-337.

Kirkup, Gill, Anna Zalevski, Takao Maruyama, and Isma Batool. 2010. Women and Men in Science, Engineering and Technology: The UK Statistics Guide 2010.

Kronberger, Nicole, and Ilona Horwath. 2013. "The Ironic Costs of Performing Well: Grades Differentially Predict Male and Female Dropout From Engineering." Basic and Applied Social Psychology 35 (6): 534-546. doi:10.1080/01973533.2013.840629.

McCall, Leslie. 2005. “The Complexity of Intersectionality.” Signs 30 (3): 1771-1800. http://www.jstor.org/stable/10.1086/426800.

O'Keeffe, Moira. 2013. "Lieutenant Uhura and the Drench Hypothesis: Diversity and the Representation of STEM Careers." International Journal of Gender, Science and Technology 5 (1): 4-24.

http://genderandset.open.ac.uk/index.php/genderandset/article/viewArticle/265.

OECD. 2014. Education at a Glance 2014. OECD Indicators.

Ohland, Matthew W., Catherine E. Brawner, Michelle M. Camacho, Richard A. Layton, Russel A. Long, Susan M. Lord, and Mara H. Wasburn. 2011. "Race, Gender, and Measures of Success in Engineering Education." Journal of Engineering Education 100 (2): 225-252. http://onlinelibrary.wiley.com/doi/10.1002/j.21689830.2011.tb00012.x/abstract. 
Pillis, Emmeline De, Lisette De Pillis, Emmeline de Pillis, and Lisette de Pillis. 2008. "Are Engineering Schools Masculine and Authoritarian? The Mission Statements Say Yes." Journal of Diversity in Higher Education 1 (1): 33-44. doi:10.1037/1938-8926.1.1.33.

Pourrat, Yvonne. 2005. Creating Cultures of Success for Women Engineers. Synthesis Report.

Primack, Richard B., and Virginia O'Leary. 1993. "Cumulative in the Disadvantages Women Ecologists." BioScience 43 (3): 158-165.

Radinger, Regina, and Guido Sommer-Binder. 2013. Bildung in Zahlen 2011/12. Schlüsselindikatoren Und Analysen.

Ratzer, Brigitte, Sonja Hnilica, Bente Knoll, and Elke Szalai. 2006. Erster Zwischenbericht Gender in Die Lehre (GiL).

http://www.tuwien.ac.at/fileadmin/t/gender/projekte/GiL/GiL_Zwischenbericht1.pdf.

Robnett, Rachael. 2013. "The Role of Peer Support for Girls and Women in the STEM Pipeline: Implications for Identity and Anticipated Retention." International Journal of Gender, Science and Technology 5 (3): 232-253.

Sagebiel, Felizitas, and Jennifer Dahmen. 2006. "Masculinities in Organizational Cultures in Engineering Education in Europe: Results of the European Union Project WomEng." European Journal of Engineering Education 31 (1): 5-14. doi:10.1080/03043790500429922.

Sarcletti, Andreas, and Sophie Müller. 2011. "Zum Stand Der Studienabbruchforschung. Theoretische Perspektiven, Zentrale Ergebnisse Und Methodische Anforderungen an Künftige Studien.” Zeitschrift Für Bildungsforschung 1 (3): 235-248. doi:10.1007/s35834-011-0020-2.

Solga, Heike, and Lisa Pfahl. 2009. "Doing Gender Im Technisch-Naturwissenschaftlichen Bereich.” In Förderung Des Nachwuchses in Technik Und Gesellschaft, edited by Joachim Milberg, 155-218. Berlin, Heidelberg: Springer-Verlag. doi:10.1007/978-3642-01123-8.

Swail, Watson Scott, Kenneth E. Redd, and Laura W. Perna. 2003. "Retaining Minority Students in A Framework for Success." ASHE-ERIC Higher Education Report 30 (2). Wiley Subscription Services, Inc., A Wiley Company: 1-187. doi:10.1002/aehe.3002.

Tinto, Vincent. 1975. "Dropout from Higher Education: A Theoretical Synthesis of Recent Research." Review of Educational Research 45 (1): 89-125. http://www.jstor.org/stable/10.2307/1170024.

Tinto, Vincent. 1997. "Classrooms as Communities." The Journal of Higher Education 68 (6): 599-623.

http://jesserbishop.wiki.westga.edu/file/view/Tinto_Classrooms+as+Communities.pdf.

Tonso, Karen L. 2006a. Student Engineers and Engineer Identity: Campus Engineer Identities as Figured World. Cultural Studies of Science Education. Vol. 1. doi:10.1007/s11422005-9009-2.

Tonso, Karen L. 2006b. "Teams That Work: Campus Culture, Engineering Identity, and Social Interactions." Journal of Engineering Education 95 (1): 25-37.

Tonso, Karen L. 2014. "Making Science Worthwhile: Still Seeking Critical, Not Cosmetic, Changes." Cultural Studies of Science Education 9 (2): 365-368. doi:10.1007/s11422012-9448-5.

Unger, Martin, Angelika Grabher, Petra Wejwar, and Andrea Laimer. 2012. Internationale Mobilität. Zusatzbericht Der Studierenden-Sozialerhebung 2011. 
Unger, Martin, Angela Wroblewski, Rossalina Latcheva, Sarah Zaussinger, Julia Hofmann, and Christoph Musik. 2009. Frühe Studienabbrüche an Universitäten in Österreich. Wien.

van den Bogaard, M. 2012. "Explaining Student Success in Engineering Education at Delft University of Technology: A Literature Synthesis." European Journal of Engineering Education 37 (1): 59-82. doi:10.1080/03043797.2012.658507.

Verloo, Mieke. 2013. "Intersectional and Cross-Movement Politics and Policies: Reflections on Current Practices and Debates." Signs 38 (4): 893-915.

http://www.jstor.org/stable/10.1086/669572.

Vogt, Christina M., Dennis Hocevar, and Linda Serra Hagedorn. 2007. “A Social Cognitive Construct Validation: Determining Women' S and Men' S Success in Engineering Programs." The Journal of Higher Education 78 (3): 337-364.

Wächter, Christine. 2007. "Nachhaltige Ingenieurausbildung." In "Gender and Science”. Perspektiven in Den Natur- Und Ingenieurwissenschaften., edited by Carmen LeichtScholten, 109-118. Bielefeld: [transcript].

Welde, Kris De, and S Laursen. 2011. "The Glass Obstacle Course: Informal and Formal Barriers for Women Ph. D. Students in STEM Fields." International Journal of Gender, Science and Technology 3 (3): 571-595. http://genderandset.open.ac.uk/index.php/genderandset/article/viewArticle/205.

Wolffram, Andrea, Wibke Derboven, and Gabriele Winker. 2009. "Women Withdrawers in Engineering Studies: Identity Formation and Learning Culture as Gendered Barriers for Persistence?" Equal Opportunities International 28 (1): 36-49. doi:10.1108/02610150910933622.

Zaussinger, Sarah, Angelika Grabher, Lukas Dünser, Andrea Laimer, and Martin Unger. 2012. Internationale Studierende. Zusatzbericht Der Studierenden-Sozialerhebung 2011. Vienna. 